\title{
Photorelease of phosphates: Mild methods for protecting phosphate derivatives
}

\author{
Sanjeewa N. Senadheera§, Abraham L. Youseffl and Richard S. Givens ${ }^{*}$
}

\section{Full Research Paper}

Address:

Department of Chemistry, University of Kansas, Lawrence, Kansas 66045, U.S.A

\section{Email:}

Richard S. Givens* - givensr@ku.edu

* Corresponding author

$\S$ Present address: Department of Medicinal Chemistry, University of

Kansas, Lawrence, Kansas 66045, U.S.A.

I Present address: Department of Chemistry, Sweet Briar College,

Sweet Briar, VA 24595, U.S.A.

\section{Keywords:}

caged phosphates; hydroxynaphthylacetyl; organophosphorus;

photo-Favorskii rearrangement; photoremovable protecting groups
Beilstein J. Org. Chem. 2014, 10, 2038-2054.

doi:10.3762/bjoc. 10.212

Received: 22 May 2014

Accepted: 07 August 2014

Published: 29 August 2014

This article is part of the Thematic Series "Organophosphorus chemistry".

Guest Editor: P. R. Hanson

(C) 2014 Senadheera et al; licensee Beilstein-Institut.

License and terms: see end of document.

\begin{abstract}
We have developed a new photoremovable protecting group for caging phosphates in the near UV. Diethyl 2-(4-hydroxy-1-naphthyl)-2-oxoethyl phosphate (14a) quantitatively releases diethyl phosphate upon irradiation in aq $\mathrm{MeOH}$ or aq $\mathrm{MeCN}$ at $350 \mathrm{~nm}$, with quantum efficiencies ranging from 0.021 to 0.067 depending on the solvent composition. The deprotection reactions originate from the triplet excited state, are robust under ambient conditions and can be carried on to $100 \%$ conversion. Similar results were found with diethyl 2-(4-methoxy-1-naphthyl)-2-oxoethyl phosphate (14b), although it was significantly less efficient compared with 14a. A key step in the deprotection reaction in aq $\mathrm{MeOH}$ is considered to be a Favorskii rearrangement of the naphthyl ketone motif of 14a,b to naphthylacetate esters 25 and 26. Disruption of the ketone-naphthyl ring conjugation significantly shifts the photoproduct absorption away from the effective incident wavelength for decaging of 14, driving the reaction to completion. The Favorskii rearrangement does not occur in aqueous acetonitrile although diethyl phosphate is released. Other substitution patterns on the naphthyl or quinolin-5-yl core, such as the 2,6-naphthyl 10 or 8-benzyloxyquinolin-5-yl 24 platforms, also do not rearrange by aryl migration upon photolysis and, therefore, do not proceed to completion. The 2,6-naphthyl ketone platform instead remains intact whereas the quinolin-5-yl ketone fragments to a much more complex, highly absorbing reaction mixture that competes for the incident light.
\end{abstract}

\section{Introduction}

Phosphates have long held an important formative position in the development of organic photochemistry beginning with the seminal report by Havinga [1] of the unusual substituent effects in the photosolvolysis of aryl phosphates that showed unexpectedly pronounced meta activation of substituted aryl phosphates. A strong 'meta effect' resulting in enhanced reaction efficiency 
by electron withdrawing, meta substituents is contrary to their ground state effects on solvolysis reactions which, instead, display enhanced reactivity for para substituents. This contrasting substituent reactivity is a consequence of two different potential energy surface (PES) contours that control the reactivity, an observation first rationalized by Zimmerman through a comparison of the change in PES electron distribution in the ground (HOMO) and excited states (LUMO) using Hückel molecular orbital theory [2,3], subsequently attributed by him to the positioning of conical intersections between the HOMO-LUMO PE surfaces [4,5]. He termed this phenomenon the "meta effect", and generalized it for photochemical solvolysis reactions. Several additional photosolvolysis studies substantiated the generality of the meta effect for phosphate leaving groups in heterolytic photoreactions.

Over the past four decades, additional examples of phosphate esters attached to reactive chromophores other than phenyl and benzyl [6-11] have been investigated for their propensity to undergo heterolytic photosolvolysis reactions, most notably $o$-nitrobenzyl (o-NB) [12], benzyl phenyl ketone (benzoin) $[13,14]$, coumarin-4-ylmethyl [15], and, more recently, p-hydroxyphenacyl (pHP) [15] phosphate esters (Figure 1). While these chromophores exhibit a range of photophysical properties, all share a conjugated aromatic structural motif that facilitates UV-vis absorption and serves as a traceless reagents, orthogonal to common ground state deprotection processes and essentially independent of $\mathrm{pH}$ effects. Thus, the chromophores are particularly useful at neutral $\mathrm{pH}$ and no added reagents are required for protecting group release.

Many photosolvolysis studies have targeted key biological substrates [6,8-12] for mechanistic and phenomenological studies. The culmination of these studies has resulted in the development of an entirely new branch of photochemistry with application in both organic chemistry and biochemistry. The reagents are generally described as "caged" compounds or photoremovable protecting groups (PPGs) in which the attached chromophore masks the biological activity of a substrate. Irradiation releases the substrate, allowing it to return to its normal bioactivity.

The desirable properties of any new PPG candidate are 1) absorption at wavelengths near or above $400 \mathrm{~nm}, 2$ ) enhanced chemical and photochemical quantum yields and 3) improved rate of release, ideally in the range of ps to ns time constants; all three are useful properties for applications in organic chemistry and biochemistry, but they are particularly important for mechanistic studies in biochemistry and biophysics [6,8-11]. Most PPG candidates require sufficiently high energy excited states for heterolysis of a carbon-oxygen or carbon-heteroatom bond that binds the chromophore to a substrate. This limits the useful absorption range to ca. 350 to $400 \mathrm{~nm}$ for heterolysis by a primary photochemical pathway.

Phosphates hold a central historic position in caged photochemistry through their cross-disciplinary significance in both biology and chemistry. Nucleotides (especially ATP, cAMP, and GTP) were among the first to be covalently bound to chromophores in a cage or PPG format that were demonstrably released upon photolysis. Benzoin caged cAMP and $o$-nitrophenethyl caged ATP, seminal examples of caged phosphates, are often the two classic caged biochemical substrates cited [6-13,15-17]. Subsequent interest in and application of PPGs has exploded largely because they provide researchers in interdisciplinary fields with a tool for initiating biological [18] and chemical processes $[6,8,10,11]$ by remote control with light as the activator. Spatial, temporal and concentration parameters for releasing substrates are controlled by adjusting the focus, time resolution, and intensity of the light source in conjunction with other variables such as the photochemical reactivity and molecular reaction pathway. Since photolysis reactions are generally considered to be kinetically much faster than ground state processes (most photorelease rates have sub $\mu$ sec time<smiles>[X]C(OP(=O)(OCC)OCC)(c1ccccc1[N+](=O)[O-])C(C)(C)OCC</smiles>

o-nitrobenzyl (o-NB)

1a, $X=1$

1b, $X=2$<smiles>[X]c1cc([X])cc(C(OP(=O)(OCC)OCC)C(=O)c2ccccc2)c1</smiles>

benzoin

2a, $\mathrm{X}=\mathrm{H}$

b, $X=O M e$<smiles>[X]c1ccc2c(COP(=O)(OCC)OCC)cc(=O)oc2c1</smiles><smiles>CCOP(=O)(OCC)OCC(=O)c1ccc(O)cc1</smiles>
coumarin-4-ylmethyl
3a, $\mathrm{X}=\mathrm{OH}$
b, $X=O M e$
c, $\mathrm{X}=\mathrm{NMe}_{2}$

p-hydroxyphenacyl (pHP)

4a

Figure 1: Common photoremovable protecting groups (PPGs) for phosphates depicted as diethyl phosphate (DEP) esters. 
constants), the use of time resolved lasers to activate PPGs offers much greater temporal resolution and more precise spatial control of the reaction variables in chemical processes, increasingly important features for biophysics and biochemistry.

Our studies on photosolvolysis reactions have uncovered several new chromophores with superior PPG properties amenable to photodeprotection. Earlier work defined the advantages and limitations of $p$-hydroxyphenacyl $(\mathrm{pHP}, 4)$, a PPG that is now finding application in biochemistry and chemistry [15]. We now report new pHP analogs with a fused aromatic or heteroaromatic extension of pHP. Our intent was to impose the pHP motif on the naphthyl and indolin-5-yl platforms (maintaining the critical substituent pattern) in order to foster aryl ketone migration by a photo-Favorskii rearrangement concomitant with ligand release. The combination of these features shifts and extends the chromophore, exhibiting a more intense, broader absorption band closer to the visible region, making the PPG more accessible for photodeprotection. Thus, elaborating the two motifs by optimally appending a hydroxy and carbonyl positioned for excited state interaction, in accord with the pHP motif 4a, invited serious examination.

\section{Results \\ Synthesis of phosphate esters}

A series of diethyl phosphate (DEP) esters caged with extended 2-(6-hydroxynaphthalen-2-yl)-2-oxoethyl (2,6-HNA, 10), 2-(4hydroxynaphthalen-1-yl)-2-oxoethyl (1,4-HNA, 14a) and its methoxy ether (1,4-MNA, 14b), and 8-(benzyloxy)quinolin-5yl)-2-oxoethyl (5,8-BQA, 24), each modeled after the p-hydroxyphenacyl (pHP, 4) chromophore were synthesized as illustrated in Scheme 1 and Scheme 2.

Synthesis of the extended 2,6-HNA phosphate ester 10 was accomplished by first demethylating 2-acetyl-6-methoxynaph-<smiles>[R]CC(=O)c1ccc2cc(OC(C)(C)C)ccc2c1</smiles>

10, 2,6-HNA DEP

B<smiles>COc1cccc2ccccc12</smiles>
11

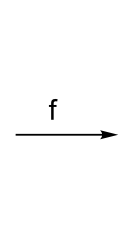<smiles>[R]CC(=O)c1ccc(OC)c2ccccc12</smiles>

c<smiles>[R][R]([H])=[13C]1CC1</smiles>

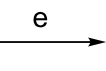<smiles>CCOP(=O)(OCC)OCC(=O)c1ccc(OC)c2ccccc12</smiles>

14b, 1,4-MNA DEP

C<smiles>CC(=O)c1ccc(O)c2ccccc12</smiles>

15<smiles>[R]CC(=O)c1ccc(O[R5](C)(C)C)c2ccccc12</smiles>

$16 \mathrm{R}=\mathrm{H}$<smiles>O=C(CBr)c1ccc(O)c2ccccc12</smiles>

18<smiles>CCOP(=O)(OCC)OCC(=O)c1ccc(O)c2ccccc12</smiles>

14a, 1,4-HNA DEP

Scheme 1: Synthesis of 2,6-HNA DEP (10), 1,4-HNA DEP (14a), and 1,4-MNA DEP (14b) DEP esters. Reagents and conditions: a) PhSH, $\mathrm{K}_{2} \mathrm{CO}_{3}$,

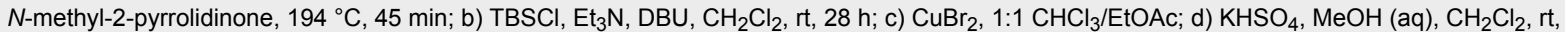
$43 \mathrm{~h}$; e) tetramethylammonium diethyl phosphate, DMF, $55^{\circ} \mathrm{C}, 2-3 \mathrm{~h}$; f) $\mathrm{Ac}_{2} \mathrm{O}, \mathrm{AlCl}_{3}, \mathrm{CH}_{2} \mathrm{Cl}_{2}, 0^{\circ} \mathrm{C}$ to rt over $3 \mathrm{~h}$ then stirred at rt. 
thalene (5) with thiophenol and $0.1 \mathrm{~mol}$ percent potassium carbonate in $N$-methyl-2-pyrrolidinone at $194{ }^{\circ} \mathrm{C}$ [19] to generate the hydroxynaphthalene 6 (72\%) followed by protecting the hydroxy group with $\mathrm{TBSCl}$ to give $7(89 \%$, Scheme 1A). $\alpha$-Bromination with copper(II) bromide [20] gave 8 (96\%, direct bromination of 6 gave poor yields). The TBS group was removed in $30 \%$ aqueous methanol containing $10-20 \%$ methylene chloride and several molar equivalents of potassium hydrogen sulfate to provide hydroxy bromo ketone 9 (yield, 75\%) [21], which was reacted with tetramethylammonium diethyl phosphate under anhydrous conditions to afford diethyl (2-(6-hydroxynaphthalen-2-yl)-2-oxoethyl) phosphate (2,6-HNA DEP, 10, 62\%) [22].

Diethyl (2-(4-methoxynaphthalen-1-yl)-2-oxoethyl) phosphate (1,4-MNA DEP, 14b) was obtained, as shown in Scheme 1B, beginning with Friedel-Crafts acylation of 1-methoxynaphthalene (11) yielding 1-acetyl-4-methoxynaphthalene (12, 73\%). $\alpha$-Bromination with copper(II) bromide gave 13 (44\%) which was converted to the phosphate ester using tetramethylammonium diethyl phosphate in dimethoxyethane (DME) at room temperature to give diethyl (2-(4-methoxynaphthalen-1-yl)-2oxoethyl) phosphate (1,4-MNA DEP, 14b, 92\%).

The hydroxy analog (1,4-HNA DEP, 14a, Scheme 1C), was synthesized from methoxynaphthone $\mathbf{1 2}$ by demethylation with thiophenol giving acetylnaphthol 15 in moderate yield (42\%). Protection with TBSCl gave 16 (86\%) followed by $\alpha$-bromination to 17 (89\%). TBS deprotection gave 2-bromo-1-(4hydroxy-1-naphthyl)ethanone, $(\mathbf{1 8}, 59 \%)$ which was converted to diethyl (2-(4-hydroxynaphthalen-1-yl)-2-oxoethyl) phosphate (1,4-HNA DEP, 14a, 31\%) with tetramethylammonium diethyl phosphate.

Benzyl protected diethyl 2-(8-hydroxyquinolin-5-yl)-2-oxoethyl phosphate (24) was synthesized from 8-hydroxyquinoline (19) by first performing acylation [23] with acetyl chloride and then quantitatively protecting the hydroxy group as its benzyl ether [24] followed by installation of ketal protection with iodobenzene diacetate in alkaline methanol [25] to give 22 (90\%, Scheme 2). Deprotection of $\mathbf{2 2}$ with $50 \%$ acetic acid gave the $\alpha$-hydroxy ketone 23 (98\%) which was esterified with diethyl phosphoryl chloride in pyridine [26] to afford 2-(8(benzyloxy)quinolin-5-yl)-2-oxoethyl diethyl phosphate $(5,8-$ BQA DEP, 24, 30\%).

The UV-vis spectra of 1,4-substituted esters $\mathbf{1 4 a}, \mathbf{b}\left(\lambda_{\max }\right.$ range from 319 to $325 \mathrm{~nm}$ ) are substantially red-shifted relative to the pHP ester $4 \mathbf{a}\left(\lambda_{\max }\right.$ at $\left.287 \mathrm{~nm}\right)$ and exhibit molar extinction coefficients ( $\varepsilon$ ) of ca. $10^{4} \mathrm{M}^{-1} \mathrm{~cm}^{-1}$ in aq MeCN (Figure 2). For the 2,6-HNA DEP (10) and 2,6-HNA GABA, the $\lambda_{\max }$ appears at $325 \mathrm{~nm}$ whereas the $\lambda_{\max }$ for the 5,8-BQA phosphate 24 occurs at $321 \mathrm{~nm}$ in $10 \%$ aq MeCN. For the 2,6-HNA series, a strong fluorescence emission is observed at $470 \mathrm{~nm}$ as shown here for the more aqueous soluble GABA ester derivative. The 2,6-HNA GABA had better aqueous solubility for fluorescence studies. (See Supporting Information File 1 for synthetic and spectral details).

\section{Photolysis of phosphate esters}

Irradiation of 14a at $350 \mathrm{~nm}$ in Pyrex vessels under ambient conditions in $1 \%$ aq $\mathrm{CD}_{3} \mathrm{OD}$ resulted in the release of diethyl phosphate as confirmed by NMR (Scheme 3, Table 1). The protecting group underwent a photo-Favorskii rearrangement (Scheme 4), yielding predominantly methyl 4-hydroxy-1-naphthylacetate (25) with a trace amount of reduction product $\mathbf{1 5}$ (Scheme 3). In anhydrous methanol, the ratio of $\mathbf{2 5 / 1 5}$ was approximately $3: 1$. When the photolysis was performed in $10 \%$ aq $\mathrm{MeCN}, 15$ was the only assigned structure from the ${ }^{1} \mathrm{H}$ NMR spectrum of a complex product mixture.

Photolysis of the methoxy analog $14 \mathbf{b}$ under similar conditions either in $\mathrm{CD}_{3} \mathrm{OD}$ or $1 \%$ aq $\mathrm{MeCN}$ resulted in the release of DEP and formation of $\mathbf{1 2}$ as confirmed by reversed-phase HPLC

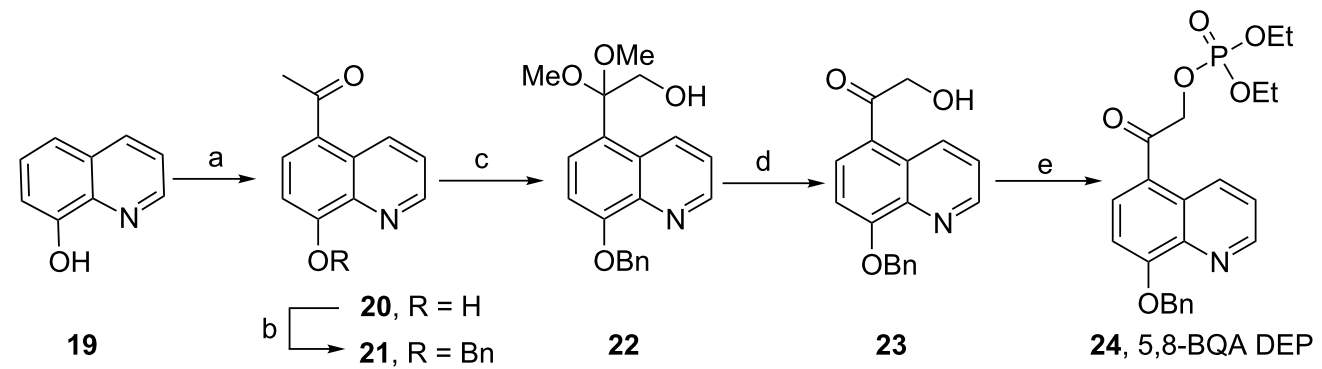

Scheme 2: Synthesis of diethyl 8-(benzyloxy)quinolin-5-yl)-2-oxoethyl phosphate (5,8-BQA DEP, 24). Reagents and conditions: (a) $\mathrm{CH}_{3} \mathrm{COCl}_{1} \mathrm{AICl}$, nitrobenzene, $14 \mathrm{~h}, 40 \%$; (b) $\mathrm{PhCH}_{2} \mathrm{Br}, \mathrm{K}_{2} \mathrm{CO}_{3}$, DMF, rt, $24 \mathrm{~h}, 100 \%$; (c) $\mathrm{Phl}(\mathrm{OAc})_{2}, \mathrm{MeOH}, \mathrm{KOH}, 0{ }^{\circ} \mathrm{C}$ to rt, $24 \mathrm{~h}, 90 \%$; (d) $50 \% \mathrm{CH}{ }_{3} \mathrm{COOH}, \mathrm{rt}, 12 \mathrm{~h}$, $98 \%$; (e) $\mathrm{P}(\mathrm{O}) \mathrm{Cl}(\mathrm{OEt})_{2}$, pyridine, $-5{ }^{\circ} \mathrm{C}$ to rt, $24 \mathrm{~h}, 30 \%$. 


\section{A. UV-vis spectrum of $14 a$}

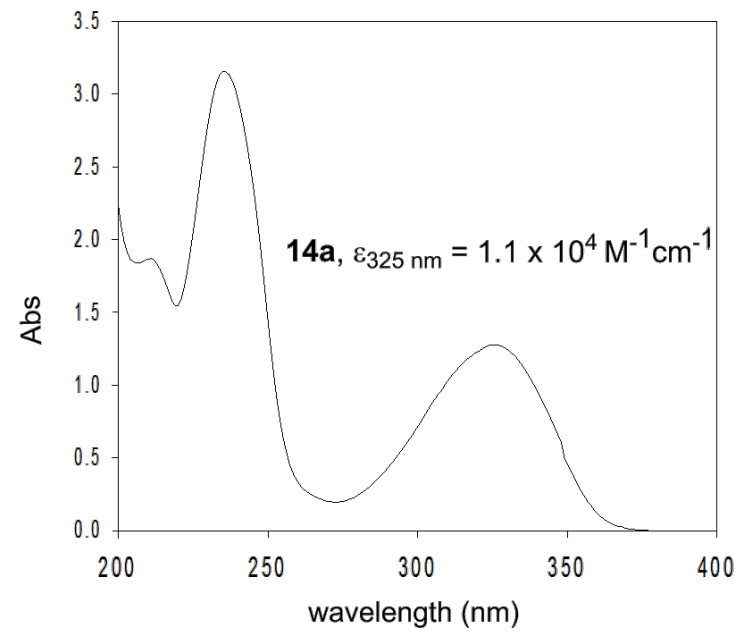

\section{B. Fluorescence spectrum of 2,6-HNA GABA}

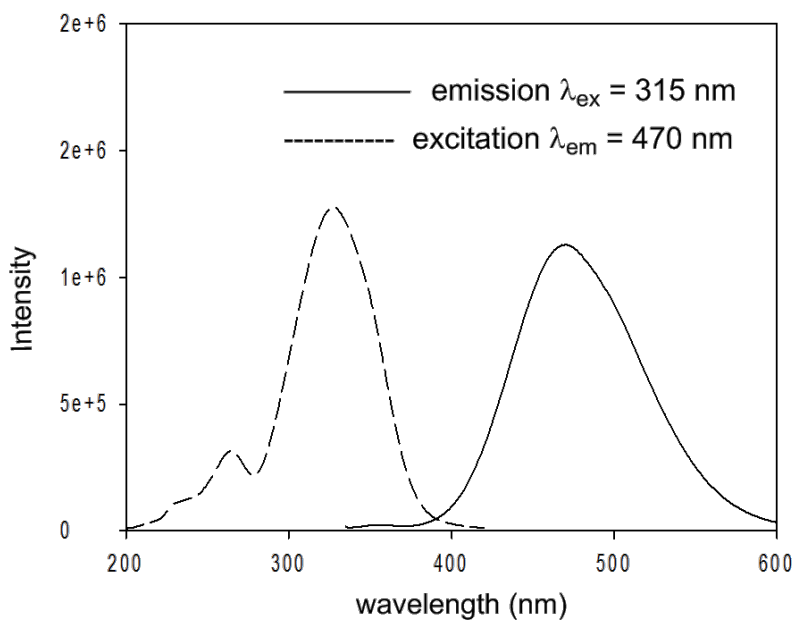

Figure 2: A. UV-vis spectrum of 14a (1,4-HNA DEP) in 1\% aq MeCN. B. Fluorescence emission/excitation spectra of 2,6-HNA GABA (0.042 mM) in pH 7.3 TRIS buffer containing $1 \%$ MeCN.<smiles>[R]Oc1ccc(C(=O)COP(=O)(OCC)OCC)c2ccccc12</smiles><smiles>[R20]c1ccc(C(C)=O)c2ccc(CC)cc12</smiles>

$15 ; \mathrm{R}=\mathrm{H}$

12; $\mathrm{R}=\mathrm{CH}_{3}$<smiles></smiles>

25; $\mathrm{R}=\mathrm{H}$

26; $\mathrm{R}=\mathrm{CH}_{3}$

Scheme 3: Photolysis of 1,4-HNA and 1,4-MNA diethyl phosphates 14a and 14b in aq $\mathrm{MeOH}$.

\begin{tabular}{|c|c|c|c|}
\hline ester & $\%$ conversion $^{a}$ & $\begin{array}{l}\text { deprotection } \\
\% \text { yield }^{b}\end{array}$ & $\Phi_{\mathrm{dis}}^{\mathrm{c}}$ \\
\hline $14 a \mathrm{OH}$ & 98 & 100 & 0.028 \\
\hline 14b OMe & 40 & 90 & 0.0076 \\
\hline
\end{tabular}

aOne hour photolysis in $\mathrm{CD}_{3} \mathrm{OD}$ at $350 \mathrm{~nm}$, determined by ${ }^{1} \mathrm{H}$ NMR using DMF as an internal standard, ${ }^{b}$ diethyl phosphate, corrected for conversion, ${ }^{c}$ determined by RP-HPLC; photolysis in $1 \%$ aqueous $\mathrm{MeOH}$.

(RP-HPLC) and NMR (Scheme 3, Table 1) but the conversion was not complete and the reaction was lethargic due to competitive absorption by the unrearranged product chromophore 12. In $1 \%$ aq $\mathrm{MeOH}$, however, the major product from the protecting group was methyl 4-methoxy-1-naphthylacetate (26) which was characterized by the signals at $\delta 4.02$ and $3.68 \mathrm{ppm}$ and confirmed by FAB-MS ( $\mathrm{m} / \mathrm{z} 230)$ and comparison with an independently synthesized sample obtained from Friedel-Crafts alkylation of 1-methoxynaphthalene (11) with methyl bromoacetate and ferric oxide [27].

Quantum yields for disappearance and percentage conversions for $\mathbf{1 4 a}$ are higher than that of $\mathbf{1 4 b}$ as indicated in Table 1. After one hour of photolysis at $350 \mathrm{~nm}$ in $\mathrm{CD}_{3} \mathrm{OD}, \mathbf{1 4 a}$ reached $98 \%$ conversion whereas $14 \mathrm{~b}$ managed to attain only $40 \%$ conversion. The disappearance quantum efficiency $\left(\Phi_{\text {dis }}\right)$ for 14a in $1 \%$ aq $\mathrm{CD}_{3} \mathrm{OD}$ was 0.028 , more than three times that for $\mathbf{1 4 b}$ under the same conditions. However, the deprotection yields for both esters were excellent, resulting in quantitative release of DEP based on conversion.

The quantitative conversion and apparent good efficiency of the 1,4-derivative 14a prompted further investigation. The quantum yield for disappearance of 14a in $1 \%$ aq $\operatorname{MeCN}\left(\Phi_{\text {dis }}=0.021\right)$ is comparable to that observed in aq $\mathrm{MeOH}\left(\Phi_{\text {dis }}=0.028\right.$, Table 1 and Table 2) but the product mixture was more complex (vide infra). Interestingly, quantum yields for the disappearance for 14a are enhanced three-fold $\left(\Phi_{\text {dis }}=0.067\right)$ when the photolysis 
<smiles>CCOCC(=O)c1ccc(O)c2ccccc12</smiles>

$14 a$ $\underset{\text { aq } \mathrm{MeOH}}{\stackrel{h v}{\longrightarrow}}$

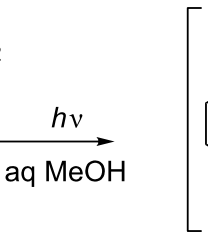<smiles>CC1CC2(C=CC1=O)CC2=O</smiles>

$-\mathrm{OPO}_{3} \mathrm{Et}_{2}$

$-\mathrm{H}^{+}$<smiles>COC(=O)Cc1ccc(O)c2ccccc12</smiles>

25

Scheme 4: The photo-Favorskii rearrangement of 14a.

solution was purged free of oxygen (Table 2). The quantum yield of 14a for the triplet sensitized photolysis in the presence of benzophenone (BP), a well-established triplet sensitizer, at $254 \mathrm{~nm}$ under $\mathrm{O}_{2}$-free conditions was $\Phi_{\text {dis }}=0.022$. These combined results demonstrate that the reactive excited state is a triplet that is partially quenched by $\mathrm{O}_{2}$ under ambient conditions.

Table 2: Photolysis of 1,4-HNA diethyl phosphate (14a) in the presence and absence of $\mathrm{O}_{2}$ and benzophenone in $1 \%$ aq $\mathrm{MeCN}$.

\begin{tabular}{ll}
$\Phi_{\text {dis }}{ }^{a}$ & conditions \\
\hline $0.067^{b}$ & degassed with Ar \\
0.022 & BP sensitized \\
0.021 & saturated with Air \\
\hline
\end{tabular}

aDetermined with RP-HPLC; ${ }^{\text {b }}$ Estimated value (see experimental section); 'Benzophenone (11 $\mathrm{mM})$ as the sensitizer and $14 \mathrm{a}(0.59 \mathrm{mM})$ in $1 \%$ aq $\mathrm{MeCN}$ at $254 \mathrm{~nm}$ and purged with $\mathrm{Ar}$.<smiles>CCOP(=O)(OCC)OCC(=O)c1ccc2cc(O)ccc2c1</smiles>

10

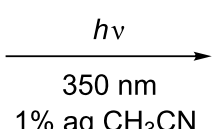
$1 \%$ aq $\mathrm{CH}_{3} \mathrm{CN}$

$\Phi_{\text {dis }}=0.031$
Irradiation of 2,6-HNA DEP (10) at $350 \mathrm{~nm}$ in $1 \%$ aq $\mathrm{MeCN}$ under conditions comparable to those employed with $14 \mathbf{a}, \mathbf{b}$ also released phosphate. The disappearance quantum yield for $\mathbf{1 0}$ $\left(\Phi_{\text {dis }}=0.031\right)$ was nearly the same as that obtained for $14 \mathbf{a}$ but the conversion after a 10 min irradiation was only $67 \%$. Unlike $\mathbf{1 4 a}, \mathbf{b}$, however, the chromophore did not undergo the photoFavorskii rearrangement, forming only the reduction product 2-acetyl-6-hydroxynaphthalene (6) in addition to other unidentified photoproducts (Scheme 5). These results paralleled our observations for $\mathbf{1 4 a}, \mathbf{b}$ in aq $\mathrm{MeCN}$.

Finally, photolysis of 5,8-BQA diethyl phosphate (24) in $10 \%$ aq $\mathrm{MeCN}$ at 300 or at $350 \mathrm{~nm}$ under degassed conditions released DEP at only $30 \%$ conversion, even after 18 hours as confirmed by both ${ }^{1} \mathrm{H}$ and ${ }^{31} \mathrm{P}$ NMR analyses (Scheme 6). The quantum yields for disappearance and product appearance $\left(\Phi_{\text {dis }}=\Phi_{\text {app }}=0.00024\right)$ were exceptionally low (Table 3$)$, considerably less than any of the naphthyl (10 and 14) or

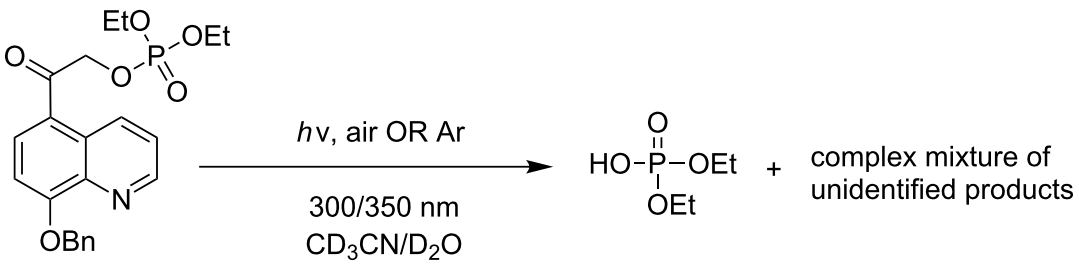


Table 3: Quantum yields and conversions of 24 with and without Ar purging.

\begin{tabular}{|c|c|c|c|c|}
\hline ester & $\begin{array}{l}\% \text { conversion } \\
\text { b } \\
\text { ambient } \mathrm{O}_{2}\end{array}$ & $\begin{array}{l}\% \text { conversion }{ }^{b} \\
\text { Ar purged }\end{array}$ & $\begin{array}{l}\Phi_{\text {dis }}\left(\times 10^{3}\right)^{\mathrm{c}} \\
\text { ambient } \mathrm{O}_{2}\end{array}$ & $\begin{array}{l}\Phi_{\text {app }}\left(\times 10^{3}\right)^{\mathrm{d}} \\
\text { ambient } \mathrm{O}_{2}\end{array}$ \\
\hline 24 & 32 & 30 & 0.24 & 0.24 \\
\hline
\end{tabular}

aSolvent was $10 \% \mathrm{H}_{2} \mathrm{O}$ in $\mathrm{MeCN}$. Photolyses were conducted with 300 or $350 \mathrm{~nm}$ lamps. betermined using ${ }^{1} \mathrm{H} \mathrm{NMR}^{\mathrm{N}}$ in $10 \% \mathrm{D}_{2} \mathrm{O}$ in $\mathrm{CD}_{3} \mathrm{CN}$;

CDetermined with ${ }^{1} \mathrm{H}$ NMR for the disappearance of the starting material at $350 \mathrm{~nm}$ with air; ${ }^{\mathrm{d}}$ Determined with ${ }^{1} \mathrm{H}$ NMR for the appearance of diethyl phosphate at $350 \mathrm{~nm}$ with air.

phenacyl (4a) analogs (see Table 4, Discussion section). A complex product mixture of byproducts of the indolinyl chromophore was obtained which was not investigated further.

\section{Discussion}

In our design of new PPG chromophores, we have attempted to circumvent or avoid the inherent deficiencies of the classical o-NB, benzoin, and coumaryl analogs (see Figure 1). A noisome limitation of o-NB PPGs that mitigate their general use in biological and mechanistic studies are their inherently slow reaction rates. o-NB rate constants are decidedly among the slowest for a photochemical heterolysis (e.g., usually not larger than $\mu$ sec time constants) due to mechanistic constraints imposed by the rate determining step of a ground state hemiacetal hydrolysis, generated photochemically, that releases the substrate. Furthermore, the o-NB PPG chromophore, itself, is converted to an $o$-nitroso aldehyde (or ketone) that reacts with endogenous nucleophiles such as amines, thiols, etc. either present on the substrate, on target proteins or in the media. Poignant evidence of these limitations surfaced during mechanistic investigations of GAP protein GTPases and enzymatic studies of ATPase [28-34].

We $[15,28,29,35]$ and others [6-11] have successfully offered alternatives to the o-NB PPG series, initially with benzoin phosphate 2 [13,14] and coumarin-4-ylmethyl phosphate 3 . However, the chromophores for these candidates remain intact or rearrange to more strongly absorbing chromophores which compete for the effective radiation wavelengths, often resulting in incomplete conversions that compromise their synthetic utility. These chromophores and especially their photoproducts are also highly fluorescent, which frequently prove to be disadvantageous.

The recent candidates are based on a pHP motif. Phosphate esters of 10, 14, 24, and acetate 27 [19] each possess a hydroxy donor coupled with an acetyl function bearing the leaving group (Figure 3). One of these, the 5-hydroxy-1-naphthylacetyl motif as its acetate ester $\mathbf{2 7}$, has already been reported to be photochemically inert in 1:1 aq MeCN by Wan [19]. Accordingly, we did not pursue the study of 27 (vide infra). Extending the aromatic portion of the chromophore with either an added benzo or pyridyl group using the pHP model red-shifted the chromophore absorption for the remaining three, 10, 14, and 24 (e.g., the maximum of $\mathbf{4 a}$ at $280 \mathrm{~nm}$ shifted to $325 \mathrm{~nm}$ for $\mathbf{1 4 a}$ tailing nearly to $400 \mathrm{~nm}$, see Figure 2).

Similar extensions of the benzyl PPG expanding it to naphthylmethyl [35,36] (28 and 29, Figure 4) or modifications by attaching substituents to phenacyl (e.g., $\mathbf{4 b , c})$ or benzyl (30b-d) moieties, and naphthylacetyl [37] reportedly lowered the singlet and triplet state energies only modestly $[10,11]$ and were unsuitable because these chromophores remained intact and in competition for incident radiation.<smiles>CCOP(=O)(OCC)OCC(=O)c1ccc2cc(O)ccc2c1</smiles>

10

diethyl 2-(6hydroxynaphthalen-2-yl)-2oxoethyl phosphate $(2,6-$ HNA DEP)<smiles>CCOP(=O)(OCC)OCC(=O)c1ccc(Br)c2ccccc12</smiles>

$14 a, R=H$

$14 b, R=M e$

diethyl 2-(4-hydroxy-1-naphthyl)-2oxoethyl phosphate and diethyl 2-(4methoxynaphthalen-1-yl)-2-oxoethyl phosphate $(1,4-\mathrm{HNA}$ DEP and 1,4-MNA DEP<smiles>CCOP(=O)(OCC)OCC(=O)c1ccc(OCc2ccccc2)c2ncccc12</smiles>

24

diethyl 2-(8(benzyloxy)quinolin-5-yl)-2 2-(5-hydroxynaphthalen-1yl)-2-oxoethyl (1,5-HNA) BQA)<smiles>CC(=O)OCC(=O)c1cccc2c(O)cccc12</smiles>

27, acetate acetate 
<smiles>[R]c1cc([R])c(C(=O)COP(=O)(OCC)OCC)c([R])c1</smiles>

4b, $\mathrm{R}=\mathrm{H}, \mathrm{X}=\mathrm{OMe}$ $4 c, X=\mathrm{H}, \mathrm{R}=\mathrm{CH}_{3}$<smiles>CCOP(=O)(OCC)OCc1cccc2ccccc12</smiles>

28<smiles>CCOP(=O)(OCC)OCc1ccc2ccccc2c1</smiles>

29<smiles>[X]c1ccc(C([R])([R])OP(=O)(OCC)OCC)cc1[X]</smiles>

30a, $X, Y=H, R=H$

b, $X, Y=H, R=\mathrm{CH}_{3}$

c, $X=\mathrm{OMe}, Y, R=\mathrm{H}$

d, $X, R=H, Y=O M e$

Figure 4: Previously studied caged diethyl phosphate PPGs possessing aromatic (benzyl, phenacyl, and naphthylmethyl) phosphates.

Photolysis of 1,4-HNA DEP (14a) in $1 \%$ aq MeOH released DEP with modest efficiency, $\Phi=0.028$. Similarly, the methoxy analog, 1,4-MNA DEP (14b), released DEP, but with a much lower efficiency $(\Phi=0.0078)$. Both quantitatively produced DEP and, pleasingly, underwent photo-Favorskii rearrangements converting the aryl ketones to methyl naphthylacetates, blue-shifting the byproduct chromophore absorptions.

Both 14a and 14b now become the first new examples of photoFavorskii rearrangements, here on a naphthyl platform. Previous examples are limited to phenacyl frameworks [6-9,15,38,39]. It is interesting to note, however, that replacement of the $\mathrm{OH}$ with $\mathrm{OMe}$ in the 1,4-HNA series results in both lower efficiency and decreased yield, a further analogy to that found with $p$-methoxy vs $p$-hydroxyphenacyl DEPs $4 \mathbf{4 a , b}$ (Table 4) $[6,13,15,40]$ and with other leaving groups.
In contrast to the results in $1 \%$ aq $\mathrm{MeOH}$, photolysis of $\mathbf{1 4 a}, \mathbf{b}$ in anhydrous media or changing the co-solvent to $\mathrm{MeCN}$ resulted in a decrease in conversion (40-60\%) and more complex reaction mixtures. The only products identified were DEP (quantitative) and reduction products $\mathbf{1 2}$ or $\mathbf{1 5}$, signaling a change in mechanism from heterolysis to homolysis. The low conversions are primarily due to competition for incident radiation by the unrearranged byproduct chromophore $\mathbf{1 2}$ or $\mathbf{1 5}$.

The role of $\mathrm{H}_{2} \mathrm{O}$ and hydroxylic solvents observed in this series is in complete accord with solvent effects on the parent pHP photoreactions $[6,13,15,40-46]$. The photo-Favorskii reaction (Scheme 7) is favored by aqueous-based solvents that serve both as a proton donor and an acceptor to the conjugate base generated from the chromophore's triplet state heterolytic cleavage of the leaving group. The dual behavior of $\mathrm{H}_{2} \mathrm{O}$ is

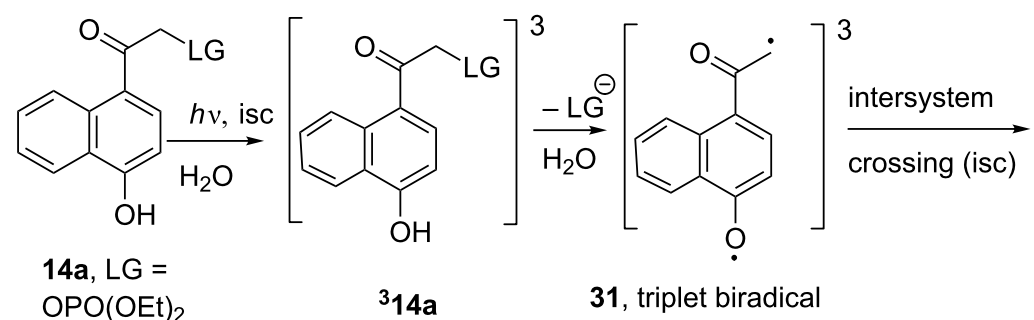<smiles>Cc1cccc2c(C(=O)O)ccc([O-])c12</smiles>

32, diradicaloid<smiles>O=C1C=CC2(CC2=O)c2ccccc21</smiles>

33, "Favorskii" intermediate<smiles>COc1cccc2c(CC(C)=O)ccc(O)c12</smiles>

25 
manifest in accepting a proton from the naphthol $\mathrm{OH}$ while simultaneously solvating the developing anionic charge on the departing nucleofuge. The resulting biradical 31, which must be a triplet by Wigner's spin rule [47] is formed from the chromophore while on the excited state PES. Intersystem crossing (isc) to a diradicaloid ground state intermediate $\mathbf{3 2}$ (vide infra) is followed by cyclization to form the 'Favorskii intermediate' 33 $[6,8,15,26,38,39,48]$.

In contrast to the 1,4-naphthyl design, neither $\mathbf{1 0}$ nor $\mathbf{2 4}$ underwent Favorskii rearrangements. While both gave stoichiometric release of DEP, the chromophores either remain intact (for 10) as also reported for other 2-naphthylacetyl analogs [49] or are consumed by oxidation and fragmentation as in the case of $\mathbf{2 4}$. Thus, the conversion and chemical yields were low and the photolysates were complex mixtures of byproducts. In the case of 24, although the reaction efficiency was insensitive to $\mathrm{O}_{2}$ (implying singlet reactivity, not quenchable by ambient $\mathrm{O}_{2}$ ), the product mixture included several oxidation byproducts of the chromophore. Thus, photoreactions of $\mathbf{2 4}$ with ambient $\mathrm{O}_{2}$ were a complication not encountered with 10 or $14 a, b$.

The failure to deconjugate the carbonyl of either chromophore by rearrangement once again impinged on the overall conversion to released substrate. The formation of competing chromophoric byproducts limits the conversion and yields $[6,10,11,15]$. For example, changing the leaving group for $\mathbf{1 0}$, i.e., photolysis of 6-hydroxy-2-naphthylacetyl GABA ester (Figure 2B) inefficiently released 4-aminobutyrate (GABA) in low yield and is absent of any chromophore rearrangement.

It is surprising that 2,6-HNA DEP (10) and Wan's 1,5-HNA acetate 27 [19] do not undergo a photo-Favorskii rearrangement. In the case of $\mathbf{2 7}$, Wan suggested that the lack of reactivity may have arisen from factors such as a lower excited state energy of the naphthyl ketone platform or the disruption of both aromatic rings for the 1,5 substituted analog 27 whereas only one ring is involved for the 1,4 substituted derivative [19].

Both of the contributing components of the 2,6 pattern, 2-naphthol $\left(E_{\mathrm{T}}=60.2 \mathrm{kcal} / \mathrm{mol}\right)$ and 2-acetylnaphthalene
$\left(E_{\mathrm{T}}=59.5 \mathrm{kcal} / \mathrm{mol}\right)$ are higher energy contributors than the same two components of the 1,4 and 1,5 patterns, 1-naphthol $\left(E_{\mathrm{T}}=58.6 \mathrm{kcal} / \mathrm{mol}\right)$ and 1 -acetylnaphthalene $\left(E_{\mathrm{T}}=\right.$ $56.4 \mathrm{kcal} / \mathrm{mol}$ ) [10,11]. Of the two motifs, the 1,4 arrangement has the lower energy triplet. Yet the 2,6 pattern with the higher triplet energy is the less reactive and fails to participate in the photo-Favorskii rearrangement.

Wan's work clearly demonstrates, however, that the excited state acidity of 1-naphthols is much greater than 2-naphthols and that excited-state intramolecular proton transfer (ESIPT) for 1-naphthols occurs at both the 5- and 8-positions by H-D exchange [19]. Furthermore, dehydration of 5-(1-hydroxyethyl)-1-naphthol (34) is very efficient, leading to quinone methide 35 which is trapped by solvent $\mathrm{MeOH}$ (Scheme 8). The corresponding 4-(1-hydroxyethyl)-1-naphthol, however, is unreactive. Comparisons of the two photoreactions, photodehydration and photo-Favorskii [48,50], and Wan's results [19] for $\mathrm{H}-\mathrm{D}$ exchange reactions demonstrate the importance of the relative location of the two functional groups and the role of ESIPT for both reactions. The hydroxy group, as Wan has elegantly determined, is the source of the acidic proton (especially for singlet state reactions). The carbonyl appendage, however, must be responsible for the enhanced heterolysis efficiency $[28,29,38]$ and may influence the formation of the triplet excited state through intersystem crossing (isc) [26] which is the origin of the heterolysis and rearrangement processes for pHP.

Wan's alternative suggestion that a disruption of both aromatic rings' $\pi$-conjugation would be less favorable than only one ring's disruption has merit. For this to be a determining factor, the disruption would have to occur prior to or during the product determining formation of the 'Favorskii' intermediate $\mathbf{3 3}$ $[38,48,50]$. The putative key intermediates for $2,6-\mathrm{HNA}$ and 1,5-HNA photo-Favorskii rearrangements (Scheme 9) illustrate the stage at which disruption in the $\pi$-network takes place. As in the case for the 1,4-HNA rearrangement, neither triplet biradical ${ }^{3} 37$ nor ${ }^{3} 40$ experience a change in connectivity within the aromatic nucleus. The formation of the triplet biradical is irreversible so that once generated, it must proceed on to a final<smiles>CC(O)c1cccc2c(O)cccc12</smiles>

34

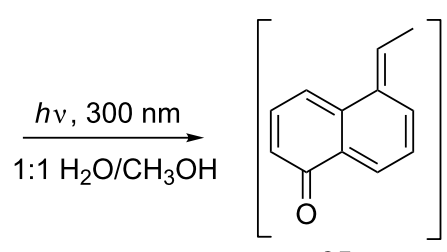

35
$\stackrel{\mathrm{CH}_{3} \mathrm{OH}}{\longrightarrow}$<smiles>COC(C)c1cccc2c(O)cccc12</smiles>

36, $48 \%, \Phi=0.84$ 
<smiles>COC(=O)c1cccc2c(O)cccc12</smiles>

\section{2,6-HNA}<smiles>COc1ccc2cc(C(=O)c3ccc4cc(C(=O)O)ccc4c3)ccc2c1</smiles>

${ }^{3} \mathbf{4 0}$, triplet biradical

40, zwitterion or biradicaloid<smiles>O=C1C=CC2=CC3(C=CC2=C1)CC3=O</smiles>

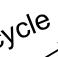

product. Since no rearrangement products are formed for either the 2,6-HNA or 1,5-HNA, it is tempting to conclude that the decay to a ground state biradicaloid or zwitterion is the product determining step. In both cases, the aromaticity of both rings is lost upon formation of the Favorskii cyclopropanone intermediates $\mathbf{3 8}$ and $\mathbf{4 1 .}$

However, this rationale also falls short because the reactions of the similar biradicaloid or zwitterion are known to undergo nucleophilic substitution and not reduction to the methyl ketone products 6,12 or 15 [38,39]. Substitution by solvent would trap the intermediate biradicaloid (or zwitterion) to form, in the case of 2,6-HNA, the $\alpha$-methoxy ketone 42, which was not detected among the photoproducts.

The controlling feature leading to the change in mechanism for these two examples is more reasonably imbedded in the route to the reactive triplet excited state configuration $[10,11]$. For $\mathrm{pHP}$, the reactive excited state is a $\pi, \pi^{*}$ triplet that is favored only in hydroxylic solvents, especially $\mathrm{H}_{2} \mathrm{O}[15,45,46,48]$. In nonhydroxylic solvents, the $\left(\mathrm{n}, \pi^{*}\right)^{3}$ dominates which leads to the classical $\alpha$ - and $\beta$-homolytic cleavage and $\mathrm{H}$-abstraction reactions. For 2,6-HNA and 5,8-BQA, the reduction product, a methyl ketone, probably results from homolysis. The lower excited state acidity and the poor intersystem crossing in the 2,6-HNA platform and strong fluorescence of the 2,6-HNA chromophore (Figure 2) also diminishes formation of the triplet and, thus, its participation in a photo-Favorskii rearrangement. Finally, an indication of the photostability of the 2,6-HNA derivatives had earlier precedence in the lack of product formation for 2-hydroxy-6-trifluoromethylnaphthylene photo-dehydrofluorination reported by Seiler and Wirz [51]. For the 1,5HNA acetate, the less reactive (higher $\mathrm{p} K_{a}$ ) of the leaving OAc group of 27 vs DEP, fluorescence decay and reversible ESIPT processes are major factors disfavoring photorelease.

A summary of the most frequently encountered examples of caged phosphates is given in Table 4. The data are reported for DEP leaving groups, when available, since DEP has proven to be a commonly employed test leaving group for PPG comparisons. It is generally found that the DEP model is reliable when extended to more complex phosphate leaving groups including nucleotides such as ATP and GTP and tyrosyl phosphates and thiophosphates [52-55]. The key comparisons for practical applications of photochemical deprotection are the maximum conversion which controls the chemical yield, the quantum 
yield (or photochemical efficiency) and the complexity of the photochemical products and byproducts in the photolyzate mixture. Solvents and excitation wavelengths are also given in Table 4 as a guide on selecting a PPG using these reaction parameters.
Table 4 reveals that most chromophores either form complex mixtures of photoproducts complicating the isolation of pure, unprotected phosphates or they remain essentially unchanged (intact) and continue to absorb incident radiation, thus compromising the conversion to products and lengthening exposure of

Table 4: A comparison of photorelease from cages for diethyl phosphates. Chemical yields, quantum yields, efficiencies and complexity based on solvents and chromophores.

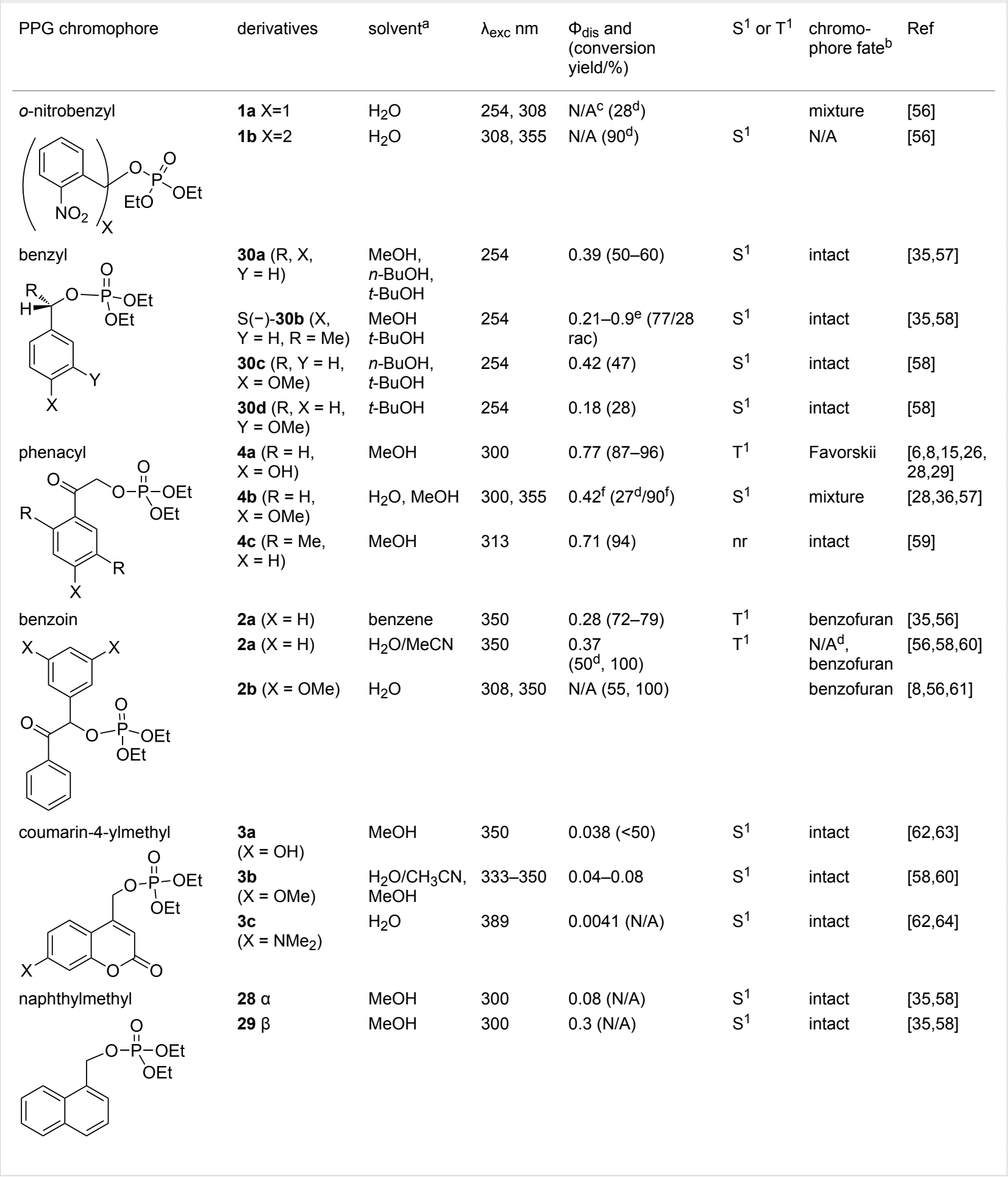




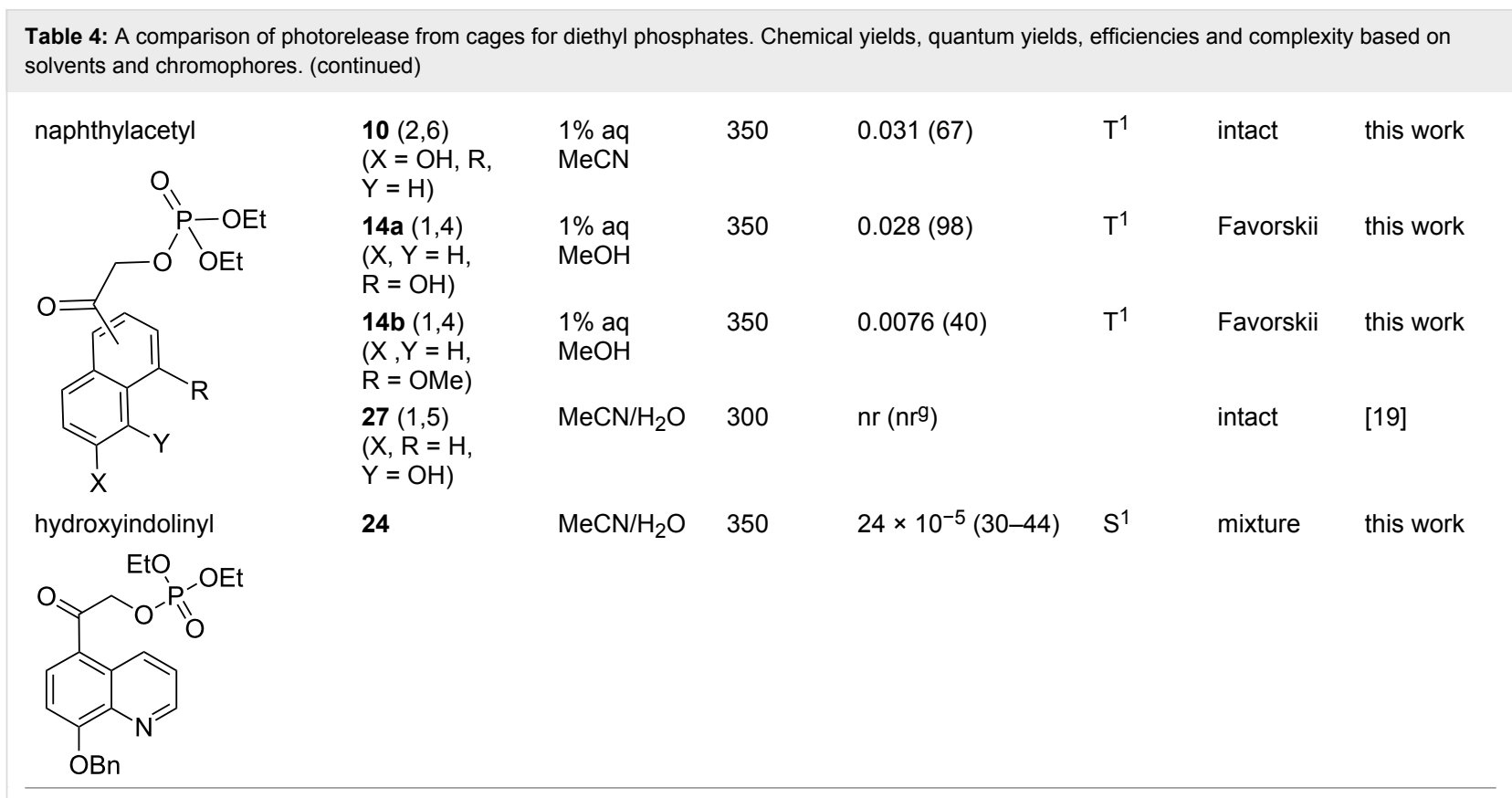

aThe ratio of $\mathrm{H}_{2} \mathrm{O} / \mathrm{MeCN}$ was $1: 1$ unless stated otherwise. b When the chromophore is unchanged upon photolysis, fate of the chromophore is noted as "intact". When the chromophore rearranges by the photo-Favorskii migration or closure to a benzofuran group, the fate is noted as Favorskii or benzofuran, respectively. When complex photoreactions occur with the chromophore, it is noted as "mixture". "N/A = not available. 'Inorganic phosphate released in $\mathrm{H}_{2} \mathrm{O}$ ([56]), "When internal return is included. ${ }^{\mathrm{f}} \mathrm{In} \mathrm{MeOH},{ }^{9} \mathrm{nr}=$ no reaction (leaving group was acetate).

the sample to radiation. Three chromophores, benzoin, $\mathrm{pHP}$, and now 1,4-hydroxynaphthylacetyl substrates cleanly undergo rearrangements that shift the absorption chromophore. Benzoins form benzofurans that, in fact, exacerbate the problem of light competition and fluorescence. Only pHP and 1,4-substituted naphthylacetyl 14 generate a less competitive chromophore allowing maximum conversion and quantitative chemical yield.

While pHP is highly efficient as a PPG ( $\Phi$ 's approach 1.0) [15] the lower efficiency of 1,4-HNA (0.028) is competitive with many currently available PPGs. A measure often applied in biological decaging studies is the product of absorptivity and efficiency $\left(\varepsilon_{\max } \times \Phi\right)$ which is 232 for photolysis of 1,4-HNA DEP at $325 \mathrm{~nm}$, competitive with PPGs listed in Table 4. By comparison, although its absorptivity is very low at $325 \mathrm{~nm}, \mathrm{pHP}$ DEP has a much larger $\varepsilon_{\max }$ at $280 \mathrm{~nm}$ that gives a value of 6000 for excitation at $280 \mathrm{~nm}$, an excitation wavelength that is biologically harmful $[6,8,9]$.

\section{Conclusion}

We have designed and tested several new candidates for nearUV absorbing photoprotecting groups. 1,4-HNA DEP (14a) and 1,4-MNA DEP (14b) upon irradiation at $350 \mathrm{~nm}$ in $1 \%$ aq $\mathrm{MeOH}$ quantitatively release diethyl phosphate concomitant with a photo-Favorskii rearrangement with quantum yields of 0.028 for $1,4-$ HNA DEP and 0.0076 for 1,4 -MNA DEP. The lower quantum efficiency of 1,4-MNA in $\mathrm{MeOH}$ is fully in accord with a similar methylation of the hydroxy group of $\mathrm{pHP}$ DEP, emphasizing the role of the phenolic $\mathrm{OH}$ on the reaction and rearrangement $[6,15,46,48]$. In anhydrous, non hydroxylic media, the mechanism of the reaction changes from heterolysis and reverts to the more traditional photochemically induced homolysis mechanism, leading to more complicated product mixtures and poor conversions.

The heterolysis mechanism of the photo-Favorskii rearrangement and release of DEP is initiated at the triplet state of $\mathbf{1 4}$ and proceeds according to the more extensively characterized rearrangement for $\mathrm{pHP}$ DEP. Due to a more favorable excitation wavelength of $350 \mathrm{~nm}$ for 1,4-HNA (vs $280 \mathrm{~nm}$ for pHP), it is anticipated that the 4-hydroxy-1-acylnaphthyl PPG will find more favorable applications as a PPG not only for phosphates but many other acidic functional groups. Additional studies on 2PE activation of 1,4-HNA DEP at $650 \mathrm{~nm}$ are also in progress.

2,6-HNA DEP and 5,8-BQA DEP also release DEP but do not undergo the beneficial aryl ketone deconjugative rearrangement, instead follow a homolytic pathway. This results in lower yields, poorer efficiencies, and incomplete conversion for 2,6HNA, and intractable mixtures of chromophoric byproducts and secondary oxidation reactions with $\mathrm{O}_{2}$, for 5,8-BQA. Neither chromophore is suitable for application as a PPG. 


\section{Experimental \\ Synthesis}

The details on the synthesis of all new compounds can be found in the Supporting Information File 1. The synthetic procedures and spectral data for all new compounds are reported in Supporting Information File 1.

\section{Photochemistry}

\section{General methods}

Photolyses were performed in a Rayonet RPR-100 photochemical reactor fitted with a merry-go-round apparatus and $16 \times 350 \mathrm{~nm}($ RPR $3500 \AA)$ or $16 \times 300 \mathrm{~nm}($ RPR $3000 \AA)$ lamps. The Rayonet reactor was turned on to warm up the lamps for 15 minutes prior to the irradiation. Samples were irradiated in NMR tubes or Pyrex test tubes at $40-45{ }^{\circ} \mathrm{C}$ in the presence of air unless indicated otherwise. The tubes were placed in a merry-go-round apparatus and the time of irradiation was recorded. Light output for the determination of quantum efficiencies was measured by using the potassium ferrioxalate method [65] under identical conditions used for the photolysis of the esters. Photolysis samples were analyzed for product formation and ester disappearance using ${ }^{1} \mathrm{H}$ NMR and RP-HPLC methods. Dimethylformamide (DMF, $2 \mu \mathrm{L}$, $2.6 \times 10^{-2} \mathrm{mmol}$ ) was used as an internal standard in ${ }^{1} \mathrm{H} \mathrm{NMR}$ analyses. For HPLC analyses the solvent was $70 \% \mathrm{CH}_{3} \mathrm{CN}$ and $30 \% \mathrm{H}_{2} \mathrm{O}$ unless otherwise noted. The detection wavelength varied depending on the ester analyzed as noted and the flow rate was $1.0 \mathrm{~mL} / \mathrm{min}$. Sample injections were performed in triplicate.

\section{Photolysis of diethyl (2-(4-methoxynaphthalen-1-yl)-} 2-oxoethyl) phosphate (14b)

An NMR tube was charged with 14b (16 mg, $0.045 \mathrm{mmol})$ along with $\mathrm{CD}_{3} \mathrm{OD}(0.95 \mathrm{~mL})$ and $\mathrm{DMF}(2 \mu \mathrm{L})$ as an internal standard. The sample was irradiated at $350 \mathrm{~nm}$ and ${ }^{1} \mathrm{H}$ NMR scans were collected after 0,30 , and $60 \mathrm{~min}$ of photolysis. The depletion of 14b and the appearance of released diethyl phosphate were quantified from the integrations of the signals at $\delta 5.4$ and $4.1 \mathrm{ppm}$, respectively. Results are shown in Table 1 .

1. Quantum efficiency determination. A Pyrex tube was charged with 14b (6.2 mg, $0.018 \mathrm{mmol})$ in methanol $(5 \mathrm{~mL})$ and water $(50 \mu \mathrm{L})$ and the contents were mixed thoroughly. The sample was irradiated at $350 \mathrm{~nm}$ and sample aliquots $(150 \mu \mathrm{L})$ were taken after $0,15,30$, and $45 \mathrm{~min}$. The aliquots were analyzed by HPLC with a mobile phase of $90 \%$ acetonitrile and $10 \%$ water and a detection wavelength of $319 \mathrm{~nm}$. The depletion of $\mathbf{1 4 b}$ was quantified from the peak areas of the signal at 3.5 min corresponding to the phosphate ester. The quantum efficiency was determined as described above. Results are shown in Table 1.
2. Photoproduct analysis in aqueous methanol. The photolysis mixture of $\mathbf{1 4 b}$ from the previous experiment was concentrated under reduced pressure and the residue washed with water and extracted with ethyl acetate. The organic extract was concentrated under vacuum and the residue analyzed with ${ }^{1} \mathrm{H}$ NMR $\left(\mathrm{CD}_{3} \mathrm{OD}\right)$ and FAB-MS. The data for the major product matched that of an authentic sample of methyl (4-methoxy1-naphthyl)acetate (26).

3. Photoproduct analysis in aqueous acetonitrile. Diethyl (2-(4-methoxynaphthalen-1-yl)-2-oxoethyl) phosphate (14b, $6 \mathrm{mg}, 0.017 \mathrm{mmol})$ was dissolved in acetonitrile $(5 \mathrm{~mL})$ containing water $(50 \mu \mathrm{L})$ in a Pyrex tube and irradiated at $350 \mathrm{~nm}$ with 9-3500 $\AA$ bulbs. Sample aliquots were taken after 0,45 , and $90 \mathrm{~min}$ of photolysis and analyzed by HPLC. The detection wavelength was $319 \mathrm{~nm}$. The phosphate ester had a retention time of $5.6 \mathrm{~min}$. A new peak emerged at 6.3 min that grew in intensity throughout the photolysis. Co-injection with an authentic sample of 1-acetyl-4-methoxynaphthalene (12) confirmed the ketone as a photoproduct from the reaction.

4. Diethyl (2-(4-methoxynaphthalen-1-yl)-2-oxoethyl) phosphate (14b): Dark reaction control experiment. An NMR tube was charged with $\mathbf{1 4 b}$ (ca. $5 \mathrm{mg}$ ), which was dissolved in methanol- $d_{4}(<1 \mathrm{~mL})$. The sample was heated to $46{ }^{\circ} \mathrm{C}$ in a warm water bath in the dark for $1 \mathrm{~h} .{ }^{1} \mathrm{H}$ NMR scans were taken before and after heating; no significant difference was observed in the NMR spectra. Also, 14a was shown to be stable for $30 \mathrm{~h}$ in $10 \% \mathrm{aq} \mathrm{MeCN}$ at $\mathrm{rt}$ in the dark.

\section{Photolysis of diethyl (2-(4-hydroxynaphthalen-1-yl)- 2-oxoethyl) phosphate (14a)}

An NMR tube was charged with 14a (17 mg, $0.05 \mathrm{mmol})$ along with $\mathrm{CD}_{3} \mathrm{OD}(0.95 \mathrm{~mL})$ and DMF $(2 \mu \mathrm{L})$. The sample was irradiated at $350 \mathrm{~nm}$ and the percent conversion and deprotection \% yield were determined as described above for $\mathbf{1 4 b}$. Results are shown in Table 1.

1. Quantum efficiency determination in aqueous methanol. The same general procedure and HPLC conditions were employed as described for 14b. Amounts used: 14a (7.6 mg, $0.022 \mathrm{mmol})$, methanol $(5 \mathrm{~mL})$, water $(50 \mu \mathrm{L})$. The detection wavelength was $323 \mathrm{~nm}$. The phosphate ester had a retention time of 3.1 min. Results are shown in Table 1.

\section{Quantum efficiency determination in aqueous aceto-} nitrile. A Pyrex tube was charged with 14a (4.7 mg, $0.014 \mathrm{mmol})$, acetonitrile $(5 \mathrm{~mL})$ and water $(50 \mu \mathrm{L})$. The sample was irradiated at $350 \mathrm{~nm}$; aliquots $(200 \mu \mathrm{L})$ were taken after $0,2,5,7$, and 10 min of photolysis and analyzed by HPLC 
on a C18 analytical column. The mobile phase contained $70 \%$ acetonitrile and $30 \%$ water, and the detection wavelength was $323 \mathrm{~nm}$. The phosphate ester had a retention time of $3.5 \mathrm{~min}$. The depletion of 14a was accompanied by the appearance of four new peaks at 1.7, 2.3, 2.6, and $3.9 \mathrm{~min}$, which were not identified. Results are shown in Table 2.

\section{Quantum efficiency determination in aqueous aceto-} nitrile (degassed). A Pyrex tube was charged with 14a (5 mg, $0.015 \mathrm{mmol})$ along with acetonitrile $(5 \mathrm{~mL})$ and water $(50 \mu \mathrm{L})$. The tube was fitted with a rubber septum and sparged with argon for $15 \mathrm{~min}$. Sample aliquots $(0.2 \mathrm{~mL})$ were taken after 0 , $2,5,7$, and $10 \mathrm{~min}$ of photolysis using a needle syringe to avoid the introduction of air into the sample during irradiation. The aliquots were analyzed as described above. The percent conversion was $44 \%$ after 2 min of photolysis, thus the first two data points from a plot of mmol 14a vs time were used to estimate the slope of the regression line for depletion of $\mathbf{1 4 a}$ which led to an approximate value of 0.067 for the disappearance quantum efficiency (Table 2).

4. Triplet sensitization experiment. A quartz tube was charged with 14a $(2.0 \mathrm{mg}, 0.0059 \mathrm{mmol})$ and benzophenone $(20 \mathrm{mg}$, $0.11 \mathrm{mmol})$, and the contents were dissolved in acetonitrile $(10 \mathrm{~mL})$ to which was added water $(100 \mu \mathrm{L})$ to make a $1 \%$ aqueous solution. The solution was degassed with argon and irradiated with 6-RPR $2540 \AA$ bulbs. Sample aliquots $(0.2 \mathrm{~mL})$ were taken after $0,2,5,7$, and $10 \mathrm{~min}$ of photolysis and analyzed by HPLC on a C18 analytical column with a mobile phase containing $70 \%$ acetonitrile and $30 \%$ water. The detection wavelength was $323 \mathrm{~nm}$. The benzophenone had a retention time of $6.5 \mathrm{~min}$ and remained constant throughout the photolysis. The phosphate ester had a retention time of $3.6 \mathrm{~min}$ and its depletion was accompanied by the appearance of three new peaks at 1.6, 1.9, and $4.4 \mathrm{~min}$, which were not assigned. The quantum efficiency was determined as described above. Results are shown in Table 2.

5. Photoproduct analysis in aqueous methanol. A Pyrex tube was charged with 14a ( $5 \mathrm{mg}, 0.015 \mathrm{mmol})$, methanol $(5 \mathrm{~mL})$ and water $(50 \mu \mathrm{L})$. The sample was irradiated at $350 \mathrm{~nm}$ for $15 \mathrm{~min}$. After photolysis the solution changed from colorless to light yellow in appearance. The solvent was removed under reduced pressure and the remaining residue was dissolved in methylene chloride and washed with water. The organic extract was collected and the solvent concentrated to afford ca. $3 \mathrm{mg}$ of an orange-colored residue. The residue was analyzed with ${ }^{1} \mathrm{H}$ NMR in methanol- $d_{4}$. Two signals were observed in the spectrum at $\delta 4.00$ and $3.68 \mathrm{ppm}$, in a ratio of ca. 1:1.5, which were assigned to the methylene and methyl protons of methyl (4-hydroxy-1-naphthyl)acetate (25), based on the similar chem- ical shifts observed for methyl (4-methoxy-1-naphthyl)acetate (26).

6. Photoproduct analysis in aqueous acetonitrile. An NMR tube containing 14a (ca. $5 \mathrm{mg}$ ) was charged with $\mathrm{CD}_{3} \mathrm{CN}$ $(1 \mathrm{~mL})$ and $\mathrm{D}_{2} \mathrm{O}(0.1 \mathrm{~mL})$. The solution was mixed thoroughly and irradiated at $350 \mathrm{~nm}$ for $30 \mathrm{~min}$. The ${ }^{1} \mathrm{H}$ NMR spectrum contained a singlet at $\delta 2.66 \mathrm{ppm}$ that was assigned to the methyl protons of 1-acetyl-4-hydroxynaphthalene (15). The presence of $\mathbf{1 5}$ was confirmed upon spiking with an authentic sample.

\section{Photolysis of diethyl (2-(6-hydroxynaphthalen-2-yl)- 2-oxoethyl) phosphate (10)}

Quantum efficiency determination. A Pyrex tube was charged with $10(2.2 \mathrm{mg}, 0.0065 \mathrm{mmol})$ along with acetonitrile $(5 \mathrm{~mL})$ and water $(50 \mu \mathrm{L})$. The solution was irradiated at $350 \mathrm{~nm}$ and sample aliquots $(200 \mu \mathrm{L})$ were taken after $0,2,5,7$, and $10 \mathrm{~min}$ of photolysis. The aliquots were analyzed by HPLC. The detection wavelength was $315 \mathrm{~nm}$. The phosphate ester had a retention time of $3.4 \mathrm{~min}$ and its depletion was accompanied by the appearance of signals at 1.8 and $4.0 \mathrm{~min}$. The quantum efficiency was determined as described above and displayed in Scheme $5\left(\Phi_{\text {dis }}=0.031\right)$.

\section{Photolysis of 4-[2-(6-hydroxy-2-naphthyl)-2- oxoethoxy]-4-oxobutan-1-aminium trifluoroacetate (2,6-HNA GABA)}

Photoproduct analysis. A Pyrex tube was charged with 2,6HNA GABA (19.5 mg, $0.068 \mathrm{mmol})$ along with acetonitrile $(1.0 \mathrm{~mL})$ and $50 \mathrm{mM}$ TRIS buffer $(9.0 \mathrm{~mL}, \mathrm{pH} 7.3)$. The solution was photolyzed at $350 \mathrm{~nm}$ for $1 \mathrm{~h}$, and sample aliquots of $50 \mu \mathrm{L}$ were taken after 0,30 , and $60 \mathrm{~min}$ of photolysis. The aliquots were diluted with $150 \mu \mathrm{L}$ of TRIS buffer and injected into an Econosphere $\mathrm{C} 18$ analytical column. The mobile phase contained $90 \% \mathrm{CH}_{3} \mathrm{CN}$ with $0.1 \%$ TFA and $10 \% \mathrm{H}_{2} \mathrm{O}$. The flow rate was $1.0 \mathrm{~mL} / \mathrm{min}$ and the detection wavelength was $244 \mathrm{~nm}$. The depletion of 2,6-HNA GABA (retention time ca. $6 \mathrm{~min}$ ) was accompanied by an increase in a peak with a retention time of ca. 3 min corresponding to the photoproduct(s). At the end of the photolysis, the solution contained an orangecolored precipitate. The organic soluble components were extracted with ethyl acetate, and the organic extract was washed with water, dried over magnesium sulfate, and the solvent removed under reduced pressure to afford ca. $6 \mathrm{mg}$ of a yellow residue. The residue was dissolved in acetonitrile and injected into the HPLC column, resulting in a peak with a retention time of ca. 3 min. Co-injection of an authentic sample of 2-acetyl-6hydroxynaphthalene (6) also produced the same peak. The residue was analyzed with ${ }^{1} \mathrm{H}$ NMR $\left(\mathrm{CDCl}_{3}\right)$ and found to contain the characteristic methyl singlet at $\delta 2.7$ ppm corres- 
ponding to $\mathbf{6}$, in addition to other unassignable peaks further downfield in the spectrum. TLC analysis with 2:1 hexane/ethyl acetate further suggested the presence of $\mathbf{6}$ as a photoproduct from the reaction.

Fluorescence measurements. A solution of 2,6-HNA GABA ( $0.042 \mathrm{mM}$ in $\mathrm{pH} 7.3$ TRIS buffer containing $1 \%$ acetonitrile) was placed in a quartz cell in a Carey Eclipse fluorescence spectrometer. Measurements were made under ambient conditions.

Photolysis of 2-(8-(benzyloxy)quinolin-5-yl)-2oxoethyl diethyl phosphate (24)

An NMR tube was charged with $24(5.0 \mathrm{mg}, 0.01 \mathrm{mmol})$ dissolved in $\mathrm{CD}_{3} \mathrm{CN}(900 \mu \mathrm{L}), \mathrm{D}_{2} \mathrm{O}(100 \mu \mathrm{L})$, and DMF $(2 \mu \mathrm{L}$, $\left.2.6 \times 10^{-2} \mathrm{mmol}\right)$. The sample was irradiated without degassing with $16 \times 300 \mathrm{~nm}$ or $16 \times 350 \mathrm{~nm}$ lamps and ${ }^{1} \mathrm{H}$ NMR spectra (16 scans) were collected after 0,30,60, 90, and $120 \mathrm{~min}$ of photolysis. The depletion of $\mathbf{2 4}$ and the appearance of released diethyl phosphate were quantified from the integrations of the methylene signals at $\delta 5.30 \mathrm{ppm}$ and $3.89 \mathrm{ppm}$, respectively.

1. Photolysis of 24 in the absence of oxygen. Using the same general procedure, the photolysis was repeated under degassed conditions. In these experiments, photolysis samples were purged with argon for 30 min before photolysis. The results are shown in Table 3.

2. Photoproduct analysis by ${ }^{\mathbf{1}} \mathbf{H}$ NMR. An NMR tube was charged with 24 (10 $\mathrm{mg}, 0.02 \mathrm{mmol})$ which was dissolved in $\mathrm{CD}_{3} \mathrm{CN}(900 \mu \mathrm{L})$ and $\mathrm{D}_{2} \mathrm{O}(100 \mu \mathrm{L})$. The contents were mixed thoroughly and the sample irradiated with air or under $\mathrm{Ar}$ purged conditions with $16 \times 300$ or $350 \mathrm{~nm}$ lamps. ${ }^{1} \mathrm{H}$ NMR spectra were collected after $60 \mathrm{~min}$ of photolysis and used to calculate the percent conversion. The depletion of $\mathbf{2 4}$ and the appearance of released diethyl phosphoric acid were determined from the NMR signals for the methylene protons of the phosphate ester and methylene hydrogens of diethyl phosphoric acid at $\delta 5.30 \mathrm{ppm}$ and $3.88 \mathrm{ppm}$, respectively. The photolysis sample was spiked with an authentic sample of diethyl phosphoric acid synthesized from diethyl chlorophosphate [66]. A dramatic increase in the intensities of the new methylene and methyl signals at 3.88 and $1.19 \mathrm{ppm}$, respectively, confirmed the presence of diethyl phosphate.

3. Control experiments with 24; stability in the absence of irradiation. An NMR tube was charged with 24 (10.0 mg, $0.02 \mathrm{mmol}$ ) along with $900 \mu \mathrm{L}$ of $\mathrm{CD}_{3} \mathrm{CN}$ and $100 \mu \mathrm{L}$ of $\mathrm{D}_{2} \mathrm{O}$. The contents were mixed thoroughly and warmed in a water bath at $40{ }^{\circ} \mathrm{C}$ in the dark for $2 \mathrm{~h} .{ }^{1} \mathrm{H}$ NMR analysis before and after the heating showed no significant change in the NMR spectrum. No significant change was observed when the sample was re-examined $48 \mathrm{~h}$ later.

\section{Supporting Information}

\section{Supporting Information File 1}

Synthetic procedures and spectral data for all new compounds.

[http://www.beilstein-journals.org/bjoc/content/ supplementary/1860-5397-10-212-S1.pdf]

\section{Acknowledgements}

Support of this work was provided by NIH grant R01 GM72910 (RSG) and by the University of Kansas.

\section{References}

1. Havinga, E.; De Jongh, R. O. Bull. Soc. Chim. Belg. 1962, 71, 803-810. doi:10.1002/bscb.19620711131

2. Zimmerman, H. E.; Sandel, V. R. J. Am. Chem. Soc. 1963, 85, 915-922. doi:10.1021/ja00890a019

3. Zimmerman, H. E.; Somasekhara, S. J. Am. Chem. Soc. 1963, 85, 922-927. doi:10.1021/ja00890a020

4. Zimmerman, H. E. J. Am. Chem. Soc. 1995, 117, 8988-8991. doi:10.1021/ja00140a014

5. Buck, A. T.; Beck, C. L.; Winter, A. H. J. Am. Chem. Soc. 2014, 136, 8933-8940. doi:10.1021/ja501777r

6. Klán, P.; Šolomek, T.; Bochet, C. G.; Blanc, A.; Givens, R.; Rubina, M.; Popik, V.; Kostikov, V.; Wirz, J. Chem. Rev. 2013, 113, 119-191. doi:10.1021/cr300177k

7. Bochet, C. G.; Blanc, A. In CRC Handbook of Organic Photochemistry and Photobiology, 3rd ed.; Griesbeck, A. G.; Oelgemöller, M.; Ghetti, F., Eds.; CRC Press: Boca Raton, Florida, 2012; pp 73-93.

8. Goeldner, M.; Givens, R. S., Eds. Dynamic Studies in Biology; Wiley-VCH: Weinheim, Germany, 2005. doi:10.1002/3527605592

9. Mayer, G.; Heckel, A. Angew. Chem., Int. Ed. 2006, 45, 4900-4921. doi:10.1002/anie.200600387

10. Turro, N. J.; Ramamurthy, V.; Scaiano, J. C. Modern Molecular Photochemistry of Organic Molecules, 1st ed.; University Science Books: Sausalito, California, 2010.

11. Klán, P.; Wirz, J. Photochemistry of Organic Compounds: From Concepts to Practice, 1st ed.; John Wiley \& Sons: Chichester, 2009. doi:10.1002/9781444300017

12. Mewes, J.-M.; Dreuw, A. Phys. Chem. Chem. Phys. 2013, 15, 6691-6698. doi:10.1039/c3cp44338h

13. Givens, R. S.; Kueper, L. W., III. Chem. Rev. 1993, 93, 55-66. doi:10.1021/cr00017a004

14. Pincock, J. A. In CRC Handbook of Organic Photochemistry and Photobiology, 2nd ed.; Horspool, W.; Lenci, F., Eds.; CRC Press: Boca Raton, Florida, 2010; Chapter 66.

15. Givens, R. S.; Rubina, M.; Wirz, J. Photochem. Photobiol. Sci. 2012, 11, 472-488. doi:10.1039/c2pp05399c

16. Engels, J.; Schlaeger, E.-J. J. Med. Chem. 1977, 20, 907-911. doi:10.1021/jm00217a008

17. Kaplan, J. H.; Forbush, B., III; Hoffman, J. F. Biochemistry 1978, 17, 1929-1935. doi:10.1021/bi00603a020 
18. Givens, R. S.; Weber, J. F. W.; Jung, A. H.; Park, C.-H. In Methods in Enzymology; Marriott, G., Ed.; Academic Press: New York, 1998; Vol. 291, pp 1-29.

19. Lukeman, M.; Veale, D.; Wan, P.; Munasinghe, V. R. N.; Corrie, J. E. T. Can. J. Chem. 2004, 82, 240-253. doi:10.1139/v03-184

20. Bauer, D. P.; Macomber, R. S. J. Org. Chem. 1975, 40, 1990-1992. doi:10.1021/jo00901a027

21. Arumugam, P.; Karthikeyan, G.; Perumal, P. T. Chromatographia 2004, 33, 1146-1147.

22. Zwierzak, A.; Kluba, M. Tetrahedron 1971, 27, 3163-3170. doi:10.1016/S0040-4020(01)98109-8

23. Matsumura, K. J. Am. Chem. Soc. 1930, 52, 4433-4436. doi:10.1021/ja01374a037

24. Iwakuma, T.; Tsunashima, A.; Ikezawa, K.; Takaiti, O. Novel carbostyril derivative and process for preparing same. Eur. Pat. Appl. EP0147719 A2, July 10, 1985.

25. Recuero, V.; de Gonzalo, G.; Brieva, R.; Gotor, V. Eur. J. Org. Chem. 2006, 18, 4224-4230. doi:10.1002/ejoc.200600385

26. Ma, C.; Kwok, W. M.; Chan, W. S.; Zuo, P.; Kan, J. T. W.; Toy, P. H.; Phillips, D. L. J. Am. Chem. Soc. 2005, 127, 1463-1472. doi:10.1021/ja0458524

27. Gielen, H.; Alonso-Alija, C.; Hendrix, M.; Niewöhner, U.; Schauss, D. Tetrahedron Lett. 2002, 43, 419-421. doi:10.1016/S0040-4039(01)02162-1

28. Givens, R. S.; Park, C.-H. Tetrahedron Lett. 1996, 37, 6259-6262. doi:10.1016/0040-4039(96)01390-1

29. Park, C.-H.; Givens, R. S. J. Am. Chem. Soc. 1997, 119, 2453-2463. doi:10.1021/ja9635589

30. Kötting, C.; Güldenhaupt, J.; Gerwert, K. Chem. Phys. 2012, 396 72-83. doi:10.1016/j.chemphys.2011.08.007

31. Kötting, C.; Gerwert, K. Chem. Phys. 2004, 307, 227-232. doi:10.1016/j.chemphys.2004.06.051

32. Kötting, C.; Kallenbach, A.; Suveyzdis, Y.; Wittinghofer, A.; Gerwert, K. Proc. Natl. Acad. Sci. U. S. A. 2008, 105, 6260-6265. doi:10.1073/pnas.0712095105

33. Kötting, C.; Kallenbach, A.; Suveyzdis, Y.; Eichholz, C.; Gerwert, K. ChemBioChem 2007, 8, 781-787. doi:10.1002/cbic.200600552

34. Du, X.; Frei, H.; Kim, S.-H. Biopolymers 2001, 62, 147-149. doi:10.1002/bip.1007

35. Givens, R. S.; Matuszewski, B. J. Am. Chem. Soc. 1984, 106, 6860-6861. doi:10.1021/ja00334a075

36. Givens, R. S.; Athey, P. S.; Matuszewski, B.; Kueper, L. W., III; Xue, J.; Fister, T. J. Am. Chem. Soc. 1993, 115, 6001-6012. doi:10.1021/ja00067a015

37. Khade, P. K.; Singh, A. K. Tetrahedron Lett. 2007, 48, 6920-6923. doi:10.1016/j.tetlet.2007.07.155

38. Šolomek, T.; Heger, D.; Ngoy, B. P.; Givens, R. S.; Klán, P. J. Am. Chem. Soc. 2013, 135, 15209-15215. doi:10.1021/ja407588p

39. Kammath, V. B.; Šolomek, T.; Ngoy, B. P.; Heger, D.; Klán, P.; Rubina, M.; Givens, R. S. J. Org. Chem. 2013, 78, 1718-1729. doi:10.1021/jo300850a

40. Epstein, W. W.; Garrossian, M. J. Chem. Soc., Chem. Commun. 1987, 532-533. doi:10.1039/c39870000532

41. Ma, C.; Zuo, P.; Kwok, W. M.; Chan, W. S.; Kan, J. T. W.; Toy, P. H.; Phillips, D. L. J. Org. Chem. 2004, 69, 6641-6657. doi:10.1021/jo049331a

42. Chan, W. S.; Ma, C.; Kwok, W. M.; Phillips, D. L. J. Phys. Chem. A 2005, 109, 3454-3469. doi:10.1021/jp044546+
43. Ma, C.; Kwok, W. M.; Chan, W. S.; Du, Y.; Kan, J. T. W.; Toy, P. H.; Phillips, D. L. J. Am. Chem. Soc. 2006, 128, 2558-2570. doi:10.1021/ja0532032

44. Zuo, P.; Ma, C.; Kwok, W. M.; Chan, W. S.; Phillips, D. L. J. Org. Chem. 2005, 70, 8661-8675. doi:10.1021/jo050761q

45. Chen, X.; Ma, C.; Kwok, W. M.; Guan, X.; Du, Y.; Phillips, D. L. J. Phys. Chem. A 2006, 110, 12406-12413. doi:10.1021/jp064490e

46. Phillips, D. L. In Hydrogen bonding and transfer in the excited state; Han, K.-L.; Zhao, G.-J., Eds.; John Wiley \& Sons: Chichester, 2011; pp 287-312.

47. Calvert, J. G.; Pitts, J. N., Jr. Photochemistry; John Wiley \& Sons: New York, 1966; p 88.

48. Givens, R. S.; Heger, D.; Hellrung, B.; Kamdzhilov, Y.; Mac, M.; Conrad, P. G., II; Cope, E.; Lee, J. I.; Mata-Segreda, J. F.; Schowen, R. L.; Wirz, J. J. Am. Chem. Soc. 2008, 130, 3307-3309. doi:10.1021/ja7109579

49. Suzuki, T.; Kaneko, Y.; Ikegami, M.; Arai, T. Bull. Chem. Soc. Jpn. 2004, 77, 801-806. doi:10.1246/bcsj.77.801

50. Rajesh, C. S.; Givens, R. S.; Wirz, J. J. Am. Chem. Soc. 2000, 122, 611-618. doi:10.1021/ja993070i

51. Seiler, P.; Wirz, J. Tetrahedron Lett. 1971, 12, 1683-1686. doi:10.1016/S0040-4039(01)87434-7

52. Zou, K.; Miller, W. T.; Givens, R. S.; Bayley, H. Angew. Chem., Int. Ed. 2001, 40, 3049-3051. doi:10.1002/1521-3773(20010817)40:16<3049::AID-ANIE3049>3.0.CO ;2-N

53. Kawakami, T.; Cheng, H.; Hashiro, S.; Nomura, Y.; Tsukiji, S.; Furuta, T.; Nagamune, T. ChemBioChem 2008, 9, 1583-1586. doi:10.1002/cbic.200800116

54. Aemissegger, A.; Carrigan, C. N.; Imperiali, B. Tetrahedron 2007, 63, 6185-6190. doi:10.1016/j.tet.2007.03.023

55. Rothman, D. M.; Shults, M. D.; Imperiali, B. Trends Cell Biol. 2005, 15, 502-510. doi:10.1016/j.tcb.2005.07.003

56. Baldwin, J. E.; McConnaughie, A. W.; Moloney, M. G.; Pratt, A. J.; Shin, S. B. Tetrahedron 1990, 46, 6879-6884. doi:10.1016/S0040-4020(01)87875-3

57. Givens, R. S.; Athey, P. S.; Kueper, L. W., III; Matuszewski, B.; Xue, J. Y. J. Am. Chem. Soc. 1992, 114, 8708-8710. doi:10.1021/ja00048a059

58. Givens, R. S.; Matuszewski, B.; Athey, P. S.; Stoner, M. R. J. Am. Chem. Soc. 1990, 112, 6016-6021. doi:10.1021/ja00172a016

59. Klán, P.; Pelliccioli, A. P.; Pospišil, T.; Wirz, J. Photochem. Photobiol. Sci. 2002, 1, 920-923. doi:10.1039/B208171G

60. Schade, B.; Hagen, V.; Schmidt, R.; Herbrich, R.; Krause, E.; Eckardt, T.; Bendig, J. J. Org. Chem. 1999, 64, 9109-9117. doi:10.1021/jo9910233

61. Corrie, J. E. T.; Katayama, Y.; Reid, G. P.; Anson, M.; Trentham, D. R.; Sweet, R. M.; Moffat, K. Philos. Trans. R. Soc., A 1992, 340, 233-244. doi:10.1098/rsta.1992.0063

62. Schmidt, R.; Geissler, D.; Hagen, V.; Bendig, J. J. Phys. Chem. A 2005, 109, 5000-5004. doi:10.1021/jp050581k

63. Schmidt, R.; Geissler, D.; Hagen, V.; Bendig, J. J. Phys. Chem. A 2007, 111, 5768-5774. doi:10.1021/jp071521c

64. Pinheiro, A. V.; Parola, A. J.; Baptista, P. V.; Lima, J. C. J. Phys. Chem. A 2010, 114, 12795-12803. doi:10.1021/jp103045u

65. Hatchard, C. G.; Parker, C. A. Proc. R. Soc. London, Ser. A 1956, 235 , 518-536. doi:10.1098/rspa.1956.0102

66. Schole, J.; Schole, C.; Eikemeyer, J.; Krebs, H. C. Tetrahedron 1994, 50, 1125-1128. doi:10.1016/S0040-4020(01)80823-1 


\section{License and Terms}

This is an Open Access article under the terms of the Creative Commons Attribution License

(http://creativecommons.org/licenses/by/2.0), which permits unrestricted use, distribution, and reproduction in any medium, provided the original work is properly cited.

The license is subject to the Beilstein Journal of Organic Chemistry terms and conditions:

(http://www.beilstein-journals.org/bjoc)

The definitive version of this article is the electronic one which can be found at:

doi:10.3762/bjoc. 10.212 